\title{
Representação de Geossistêmas em Estudos de Arqueologia da Paisagem: Ambientes Ancestrais em Ilhéus, Nordeste do Brasil
}

\author{
Representation of Geossystens In Archaeology Landscape Studies: \\ Ancient Environments In Ilhéus, Northeastern Brazil
}

\author{
Kaique Brito Silva1, Raul Reis Amorim² \\ 1 Universidade Estadual de Campinas, kaiquesilva@ige.unicamp.br \\ 2 Universidade Estadual de Campinas, raulreis@unicamp.br
}

\begin{abstract}
Resumo: As ocupações pretéritas no espaço geográfico remontam vivências que detinham relações singulares com os atributos naturais. Nesse sentido, a Arqueologia da Paisagem tenta desvendar, através de vestígios arqueológicos, os modos de vida das populações ancestrais. A abordagem metodológica que traduz os sistemas naturais e suas relações com os sistemas antrópicos é conhecida como teoria geossistêmica, que auxilia a Arqueologia da Paisagem nos padrões de ocorrências pretéritas oriundas de configurações ambientais. O objetivo dessa pesquisa foi expor os cenários geossistêmicos de Ilhéus, Bahia, Brasil, que condicionaram as ocupações desde o período pré-colonial brasileiro. Foram identificados 4 geossistemas que definiram a forma de grupos pré-coloniais ocuparem a região, além de favorecer o crescimento da colônia a partir do século XIX através da produção de cana-de-açúcar nos engenhos locais.
\end{abstract}

Palavras-chave: Sistemas Naturais, Arqueologia da paisagem, Período Colonial, SIG.

Abstract: Ancient occupations in the geographic space go back to experiences that had singular relations with the natural attributes. In this sense, the Landscape Archaeology tries to unveil, through archaeological vestiges, the ways of life of the ancestral populations. The methodological approach that shows the natural systems and their relations with the anthropic systems is known as geosystemic theory, which assists Landscape Archaeology in the patterns of past occurrences arising from environmental configurations. The objective of research was to expose the geosystemic scenarios of Ilhéus, Bahia, Brazil, that conditioned the occupations from the Brazilian pre-colonial period. Four (4) geosystems were identified that defined the form of pre-colonial groups occupying the zone, besides favoring the growth of the colony from the nineteenth century through the production of sugar cane in the local mills.

Keywords: Natural systems, Landscape archaeology, Colonial period, GIS.

\section{Introdução}

A definição de sistemas naturais, criada em meados do século XX, traz uma perspectiva geográfica que indica uma relação sistêmica entre os atributos físicos da paisagem (rochas, solos, relevos, fauna, flora e climas), criando cenários que, a partir da escala de estudo, podem ser classificados como homogêneos ou heterogêneos no que concerne a produção de energia (alimentar ou funcional). A inserção do homem nesse contexto é traduzida como a presença, sobreposta aos sistemas naturais, de sistemas antrópicos. A junção dessas duas dimensões de observação e compreensão da paisagem é categorizada como os geossistemas. É uma abordagem atual da ciência geográfica, derivada da Teoria Geral dos Sistemas (SOCHAVA, 1971; GAGARINOVA e KOVALCHUK, 2010; BASTIAN et al., 2012; BURKHARD et al. 2012; BURKHARD et al., 2014; BASTIAN et al., 2015; AMORIM e OLIVEIRA, 2013; AMORIM et al., 2017).

Os processos que subsidiam a compartimentação da paisagem no sentido de visualizar os locais com recursos naturais primários para determinado uso, desenvolvem subdivisões que mostram por muitas vezes, em níveis detalhados, as posições no ambiente de determinadas matérias primas. Analisar a fertilidade de um 
solo, diferenciar domínios com fauna e flora propícias ao uso pelas populações, presença de água e segurança ambiental, são exemplos de percepções que indicam claramente a formação de cenários oriundos da interação entre os diversos elementos presentes no meio natural. Entretanto, considerar que os sistemas da relação sociedade e natureza é apenas uma concepção moderna de planejamento do espaço geográfico, esbarra-se ao longo dos diversos relatos científicos que estudam a evolução do homem moderno em diversos trechos do nosso tempo histórico. Nesse sentido, esforços multidisciplinares com apontamentos da História, Geografia e Arqueologia, sobre o uso do espaço, são vistos como fundamental para contribuir com conjecturas acerca da evolução do uso dos recursos naturais (BRADLEY, 2000; CLENDENON, 2009; CHLACHULA, 2001; WALSHA et al. 2017).

Atualmente, a Arqueologia da Paisagem é uma corrente epistemológica da Arqueologia clássica que considera categoricamente a produção material (e cultural) de determinada população pretérita em função das características ambientais ao redor de seus núcleos de vivência. Seja de uma comunidade ou um indivíduo, nômade ou sedentário, os vestígios encontrados evidenciam que a percepção no âmbito do sujeito é reflexo do entendimento das localidades de matéria prima e alimento, isso em qualquer lugar do planeta (BUTZER, 1982; RIVERA e ROTHHAMMER, 1990; ATTEMA e DEHAAS, 2004; SANJUÁN, 200; 5ENGLAND et al. 2008; GHEYLE, 2009; KARKANAS et al. 2011; BROWN et al. 2015). A construção da paisagem e a leitura de ambientes, dessa forma, já é algo construído em diversos recortes geográficos ao longo do tempo e, sobretudo, do espaço, já que a cênica sempre foi entender, ainda que de forma empírica, o comportamento ecológico dos territórios. Trabalhos recentes da Arqueologia da Paisagem como os de Walsh et. al (2017) na Grécia, e Casparia et al. (2017) na China, demonstram que o olhar arqueológico atual se renovou ao longo do século em função da necessidade de inserção de estudos extra sítios, onde apenas a descrição dos vestígios materiais não consegue explicar os modos de vida dos indivíduos históricos. Nesses mesmos trabalhos, ainda que o objetivo geral seja explicar de forma convencional a estrutura de um sítio arqueológico, tópicos ao longo do texto se debruçam para montar um "quebra-cabeça" formado pelas relações das comunidades ancestrais com o meio abiótico. A abordagem geográfica extra sítio, ganha força quando as ocorrências arqueológicas em estudo são ligadas as configurações de ocupação humana pós idade média, quando diretrizes coloniais ganham força no mundo, desencadeando sobretudo ocupações pautadas em leitura de ambientes (RIVEIRA e ROTHHAMMER, 1990; IRIARTE et al. 2013; OLIVEIRA et al. 2013; CASPARIA et al. 2017).

No Brasil, a formação do arcabouço histórico nacional é estritamente ligada aos fatos que envolvem as relações indígenas, escravistas e a construção do Brasil colonial, imperial e republicano. Em suma, os contos e relatos cujo descrevem e interpretam a constituição das tribos, quilombos e núcleos urbanos com presença de europeus, sempre são acompanhados de informações que indicam uma paisagem como plano de fundo para cada sistema antrópico (FIONA, 1996). Segundo Pereira e Pereira (2017), relatos coloniais acerca das características terrenas das capitanias hereditárias no Nordeste do Brasil eram recorrentes no século XVI e XVII: contextualização hidrográfica dos rios, proposições da forma da linha de costa, presença de serras e demais referenciais da paisagem eram informações primordiais para ensaios de planejamento daquela época. Além disso, a posição geográfica e o desenho de croquis regionais dos engenhos de cana-de-açúcar eram peças chaves para consolidar as ocupações ao longo das capitanias hereditárias. Entretanto, estudos arqueológicos indicam que ainda mais no passado observavam-se também descrições do comportamento geográfico das tribos indígenas presentes no território nacional, sobretudo grupos do tronco cultural tupiguarani: [1] vestígios de lascas de quartzo e sílica em ambientes a quilômetros de distância da jazida fonte e a [2] construção de sambaquis, são exemplos de como grupos de caçadores e/ou coletores além de mapear o espaço através de suas experiências, fazem com que a transformação da paisagem seja sinônimo de valor simbólico (DIAS et al, 2013).

Dessa forma, a questão central desse trabalho é: os sistemas naturais no Brasil sempre foram compreendidos e explorados de forma sistemática, em diferentes períodos históricos? Os caminhos metodológicos deste trabalho tentam evidenciar que as fontes de matéria prima, os ambientes e as possibilidades de sobrevivência (no âmbito individual ou social) sempre foram concêntricas as características ecossistêmicas. A concepção sistêmica, empiricamente, pode está sendo construída no Brasil há diversos anos, mesmo antes da chegada dos portugueses. Para captar essas afirmativas no espaço geográfico, a área de estudo do trabalho é o município de Ilhéus, na região Nordeste do Brasil. Assim como nos outros Estados nordestinos, o Estado da Bahia foi pioneiro na expansão do território e, dentro desse processo, a região de Ilhéus despõe de ocorrências arqueológicas do período colonial e vestígios de ocupações pré-coloniais. As sobreposições das ocupações humanas em diferentes anos nos mesmos redutos naturais podem subsidiar a ideia de que, os geossistemas são recortes presentes na transformação da paisagem local desde épocas mais remotas. 


\section{Aspectos Metodológicos}

\subsection{Contexto dos Sítios Regionais}

O município de Ilhéus está localizado no sul do estado da Bahia, banhado pelo Oceano Atlântico. Através dos relatos históricos, é possível visualizar que os processos de ocupação do território na região é sinônimo das atividades desenvolvidas em outras zonas de expansão territorial do Brasil, sobretudo ligados as atividades de navegação: [1] no que concerne aos remanescentes históricos, dito pós-chegada dos portugueses, a historiografia relata que o desenvolvimento local inicia-se com a criação das capitania de São Jorge dos Ilhéus, sendo a Vila de Ilhéus e suas adjacências produtores de mantimentos para abastecimento interno da colônia. Destacam-se atividades agricultoras de cana-de-açúcar, mandioca e cacau, este último já no fim do século XIX. A presença de engenhos movidos a água para a produção de açúcar e farinha era a força motriz para a popularização local, sobretudo feita por escravos ao longo dos séculos XVI e XVII. Já a pecuária sempre demonstrou ser de pequena escala, com consumo de carne oriundas de regiões do semiárido brasileiro, já que a conectividade com as regiões mais interioranas era feita através de caminhos margeando os rios regionais. Em termos de conectividade com outros centros de comércio, como Salvador (ao norte) e Porto Seguro (ao sul), a presença de um porto de escoamento na Baia do Pontal era o principal acesso de pessoas e mercadorias (SAKAI, 1979; DIAS e ARAUJO, 2016).

Em relação as ocupações identificadas como [2] pré-coloniais, os vestígios mapeados remetem a grupos caçadores coletores que possivelmente se deslocavam pelas planícies litorâneas e margens de rios desde o último evento de transgressão marinha (entre 7 e 5 mil anos antes do presente, período geológico atual do Quaternário, transição entre as épocas Pleistoceno e Holoceno). Com uma dieta de caças, colheita de frutas nativas e coleta de moluscos em ambientes estuarinos, os vestígios indicam que as relações de vivência desses grupos indígenas nos ambientes marinhos e continentais eram cotidianas. As evidências que definem esse perfil de ocupação são resultados de estudos e interpretações acerca da presença de Sambaquis (amontoados de valvas de moluscos) na costa do Brasil, também com possível presença na região de Ilhéus (DIAS e ARAÚJO, 2016). Em substratos arenosos próximos a paleoestuários, os amontoados de concha trazem em seu bojo, além de esqueletos, diversos objetos de uso substancial acompanhados de artefatos simbólicos, organizado pelos atributos culturais dessas comunidades ancestrais (ROOSEVELT et. al, 1991; DEBLASIS et al.1998; GASPAR et al. 2008; IRIART et al. 2013, WAGNER, 2014).

No município de Ilhéus, os dados primários obtidos através da prospecção arqueológica de sítios e ocorrências são resultados de pesquisas do Núcleo de Estudos e Pesquisas Arqueológicas da Bahia - NEPAB. Expostos na Figura 1, os vestígios materiais analisados pelos pesquisadores foram encontrados após análise laboratorial interpretativa da paisagem regional, considerando sobretudo uma cartografia com foco na presença de corpos d'água (motor dos engenhos e fonte de água para os antigos grupos caçadores coletores). Sendo assim, as bacias hidrográficas são os recortes espaciais para estimar locais com potencialidade a ocorrências arqueológicas. Projetos de "Mapeamento Arqueológico nas Bacias hidrográficas dos rios Almada, Cachoeira e Santana" são executados desde o início dos anos 2000, e através da coordenação do pesquisador Walter Morales, compõem resultados de pesquisas e atividades de extensão e ensino em nível estadual, favorecidos, sobretudo, pela riqueza histórica de cenários ancestrais (ARAÚJO, 2011; ARAÚJO, 2012; SILVA, 2012; DIAS et al., 2013; SILVA, 2013). Destaca-se também o fato de que a cidade de Ilhéus é concêntrica no exutório das três bacias de drenagem citadas. Pode-se afirmar que essa posição geográfica é o principal fator para uma sobreposição de populações de diferentes momentos ao longo do tempo que utilizaram recursos naturais dos geossistemas locais.

\subsection{Abordagem Sistêmica}

Considerando que a paisagem é o "plano de fundo" para identificar os tipos de uso da terra sobre os sistemas naturais regionais, os resultados de uma leitura geossistêmica de ambientes sempre perpassarão na construção de representações espaciais, que é o produto tangível dessa metodologia: além da necessidade de possuir habilidades para estruturar as unidades da paisagem (geologia, geomorfologia, solos, fauna e flora), o observador deve-se atentar as escalas em estudo, sobretudo considerando a noção de espaço de vivência que alterna conforme o nível de demanda por recursos e percepção ambiental entre as ocupações ancestrais ao longo do tempo. Nesse sentido, Amorim et al. (2017) compartimenta quatro (4) escalas de estudos geossistêmico, atribuídos aos elementos do geossistema: [1] fáceis e [2] tratos, que são as transformações da paisagem observadas no nível individual, ou seja, as ações do sujeito histórico na construção de um abrigo, área de cultivo, tribos, aldeamentos, dentre outros. Esse nuance só pode ser retratado em escala de detalhe; [3] O complexo de tratos ou localidades são resultados da homogeneização da paisagem, quando as transformações antrópicas são camufladas por uma matriz de paisagem natural, como a ocorrência de pequenos 
aldeamentos camuflados por um ambiente florestal; [4] Paisagem conceitual, onde o foco da representação dos geossistemas são os dimensionamentos dos elementos do meio físico, como um complexo montanhoso, ambientes litorâneos, complexos de cavernas, dentre outros.

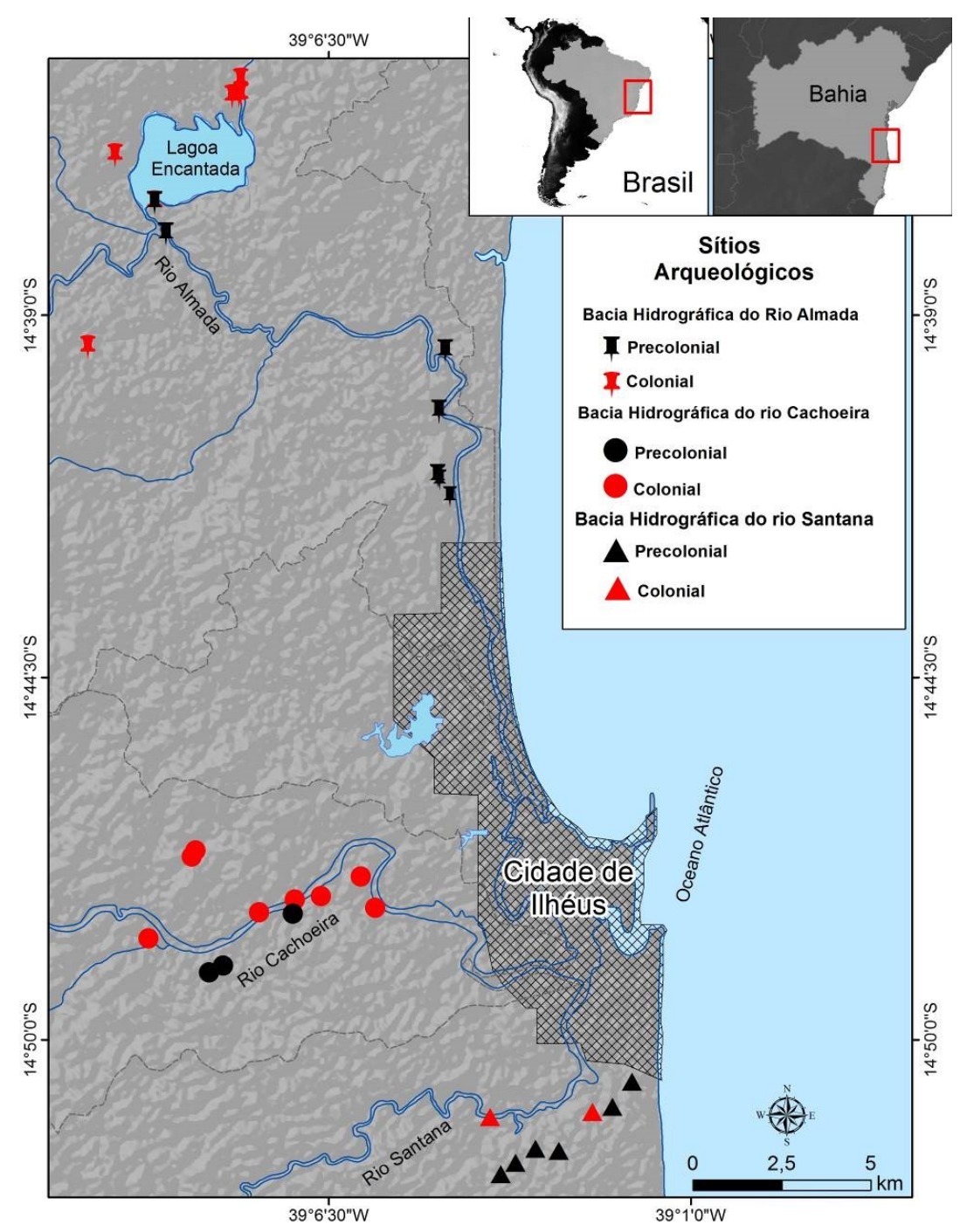

Figura 1 - Ocorrências arqueológicas por bacias hidrográficas na região de Ilhéus.

Conforme exposto, percebe-se que a quantidade de informações primárias e o recorte em estudo, definem a representação geossistêmica a ser empregada: no presente estudo, a paisagem conceitual é a categoria de análise geossistêmica a ser concebida, considerando que as ocupações na região de Ilhéus estão intimamente ligadas a configuração do meio físico regional. Dessa forma, em níveis de detalhados, a contextualização das ocorrências arqueológicas poderia se apresentar destoantes, já que são vestígios atribuídos a diferentes períodos históricos. Dessa forma, a partir de escala de estudo regional, observados também nas pesquisas de Isachenko (1973) e Gagarinova e Kovalchuk (2010), a representação dos sistemas naturais da área em estudo compreendeu o cruzamento das informações inerentes as:

(1) Formas de Relevo - Define a compartimentação das formas de relevo derivadas de topossequência, tendo como auxílio à construção de unidades gerais de dissecação e deposição;

(2) Substrato - São as características gerais das formações superficiais, sejam sedimentos, pedimentos, mantos de alteração e perfis pedológicos. No presente estudo, as informações são pedológicas.

(3) Domínio morfoestrutural - Conjunto de rochas que deu origem ao substrato. Considerando que o mapeamento geológico a ser utilizado é de média e pequena escala, identificar com exatidão os limites da rocha matriz que deu origem ao substrato não se aplica, mais a formação, grupo, província ou complexo geológico, sim, uma vez que, os processos atuantes nesta gênese desse conjunto de rochas, apontam muito sobre seu comportamento nos processos intempéricos na paisagem (SOARES e AQUINO, 2012). 
Como exemplo prático, Dias et al. (2015) expõe que parte da riqueza arqueológica local é resultado de ocupações que levavam em conta a presença de água em abundância na região em estudo. E como a água tem seus caminhos hidrográficos definidos pela litosfera, a metodologia de mapeamento dos sistemas naturais focou em observar as formas de relevo da área para destacar as classes do meio físico que apontem cenários de diferentes relações das ocupações (sistemas antrópicos) com a água. É nesse escopo que seguiram as linhas de pesquisa em Arqueologia da paisagem na região, pois as localidades arqueológicas apresentaram, em primeiro momento, íntima relação com as três bacias hidrográficas presentes no atual município de Ilhéus. Outro aspecto importante, é que as ocupações coloniais e pré-coloniais visualizavam também as possíveis rotas que ligavam os ambientes praianos com as zonas interioranas, fazendo com que os sistemas naturais mapeados compreendam poligonais que além da configuração do relevo, agrupasse feições correspondentes aos solos.

A diversidade de recursos na área, seja em relação a água e/ou fauna e flora, pode ser atribuída ao clima: de acordo com Cavalcanti (2016) e tradicional classificação internacional de Koppen (1936), prevalece na área os tipos climáticos $A f$ e $A w$, classificados no Brasil como Tropical Úmido de Floresta e Subúmido, respectivamente, e ambos sem estação seca definida. Ainda segundo Cavalcanti (2016), a circulação atmosférica da região é caracteziada pelos ventos alísios e frequentes zonas de convergências intertropicais, que são sinônimos de chuvas constantes. E segundo Thornthwaite (1948), Alvares et al. (2013) e Silva et al. (2017), esse clima caracteriza-se também pelas métricas de temperatura média de $24^{\circ} \mathrm{C}$, e precipitação anual próxima a $2.000 \mathrm{~mm}$. Ainda segundo os autores, os valores de chuva indicam que essa região é um domínio com níveis pluviométricos similares ao clima Amazônico (região equatorial do Brasil).

\subsection{Geoprocessamento de Dados}

Segundo Bevan (2002), o uso de Sistemas de Informações Geográficas - SIG em pesquisas que relacionam as ocupações humanas com os ambientes naturais foi o grande passo metodológico para a consolidação da Arqueologia da Paisagem. O uso dessa ferramenta permite sobrepor num mesmo ambiente digital, camadas inerentes a todos os atributos geográficos de determinada localidade ou região, sendo essa fase da pesquisa denominada de geoprocessamento. Através da formação de um banco de dados cartográficos envolvendo a posição dos sítios arqueológicos, composição de vales e serras regionais, além o tipo de solos, Bevan e Connoly (2002) conseguiram estimar as rotas de circulação, aldeamentos e demais comportamentos de ocupações ancestrais ao logo da costa mediterrânea no vale de Kythera, na Grécia, sendo um trabalho referencial para posteriores pesquisas em Arqueologia da Paisagem. Além disso, um SIG permite a modelagem de cenários a partir de informações provenientes de Sensoriamento Remoto, fazendo com que as imagens de satélite, por exemplo, sirvam não só para classificar a paisagem da área, mas também para representar as dimensões de antigas construções e sítios arqueológicos. A soma das representações da paisagem vista de cima e a percepção horizontal dos sítios arqueológicos, completam as análises que permitem afirmar que a construção de uma leitura de ambientes é realizada pelas comunidades desde épocas remotas, sendo essa a questão central para compreender as antigas ocupações humanas, conforme as inferências dos estudos arqueológicos (BEVAN, 2002; BEVAN E CONNOLY, 2004; KANTNER, 2008; DOYLE ET AL. 2011; SCHWERIN ET. AL, 2013; RISSETO E LANDAU, 2014; RISSETO 2017).

Para a região de Ilhéus, os dados cartográficos utilizados são os componentes geossistêmicos apontados: geologia, relevo e solos. Cada atributo foi georreferenciado no formato de arquivos vetoriais, disponíveis pelo Serviço Cartográfico do Estado da Bahia - SEI (2004) e refinados para a escala local nos trabalhos de Silva et al. (2015) e Franco et al. (2011). Em seguida, no SIG ArcGIS versão 10.5, os dados foram [1] importados e intercalados com as feições de relevo da região: através do comando Merge and Spatial Join, as três camadas de atributos foram mescladas, originando os polígonos correspondentes a unidades dos sistemas naturais que compartilham os mesmos atributos, ou seja, detém de geologia, relevo e solos em comum.

Posteriormente, [2] foram lançados sobre as camadas dos sistemas naturais os pontos de coordenadas geográficas dos sítios e ocorrências arqueológicas regionais, derivadas dos trabalhos de Araújo (2011), Araújo (2012), Silva (2012), Silva (2013) e Dias et al. (2013). No total são 32 pontos correspondentes as antigas ocupações pré-coloniais e coloniais (Quadro 1). Por fim, [3] foi adicionada a camada de hidrografia disponível também no banco de dados da SEI (2004).

Quadro 1 - Quantidade de Vestígios arqueológicos nas bacias hidrográficas do estudo

\begin{tabular}{|c|c|c|}
\hline Bacia Hidrográfica & Ocupações Pré-Coloniais & Ocupações Coloniais \\
\hline Rio Almada & 7 & 6 \\
\hline Rio Cachoeira & 3 & 8 \\
\hline Rio Santana & 6 & 2 \\
\hline
\end{tabular}




\section{Sistemas Naturais suas Relações com Ocupaç̃̃es Pretéritas}

Os terrenos que fazem parte da atual região de Ilhéus, que outrora compuseram a capitania hereditária de São Jorge dos Ilhéus, historicamente foram destacados pela evidente distinção entre dois cenários: elevações e planícies (DIAS e ARAÚJO, 2016). Considerando a metodologia que baseada na identificação das formas de relevo, substratos e domínio morfoestrutural, os geossistemas identificados basicamente se definem a partir dos contornos específicos do relevo e suas estruturas pedológicas, que variam em seguimentos arenosos e argilosos (Figura 2).

Em relação às elevações, os morros que se configuram como limítrofes as áreas litorâneas são entendidos, desde o tempo de circulação humana colonial, como planaltos costeiros [1] a partir da representação de uma escala regional. Essa mesma configuração, no sentido ocidental (continental), é reconhecida como depressões [2], pelo fato de que os vales e os interflúvios são indissociáveis no reconhecimento da paisagem, caracterizando o relevo como "relevo de terrenos movimentados".

As planícies da área em estudo são diferenciadas entre planícies de textura arenosa e argilosa: as atividades marinhas da época geológica atual (Holoceno, iniciada há cerca de 10 mil anos) definem as mais recentes formações arenosas, geralmente traduzidas na literatura científica como planícies quaternárias. Já as atividades fluviais, sobretudo observadas nas margens do baixo curso das três bacias hidrográficas da área, definem atualmente a textura argilosa (os rios depositam sedimentos de textura argilosa provenientes dos demais compartimentos das bacias hidrográficas) das áreas mais rebaixadas no sentido continental (PEDREIRA e WAELE, 2008).

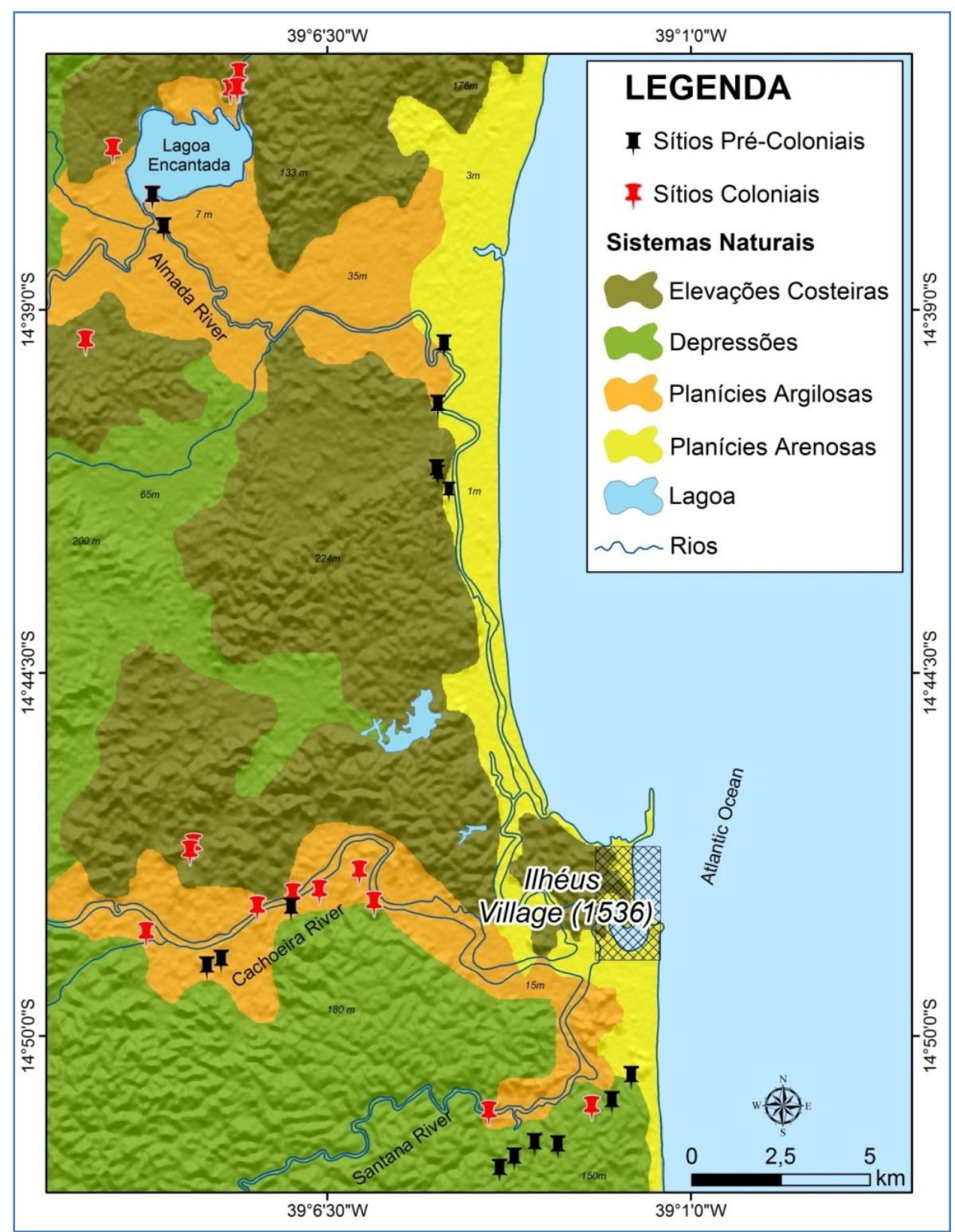

Figura 2 - Ocorrências arqueológicas e seus respectivos geossistemas. 


\subsection{Geossistemas das Matrizes Pré-Coloniais}

Como observado na Figura 2, a relação geossistêmica das ocupações pré-coloniais ocorriam mais próximas as áreas litorâneas, com preferências de circulação nas planícies da região. Tanto nas zonas arenosas de preamar (linha de costa) quanto em terrenos planos mais próximos as áreas interioranas, essas ocorrências relatam o modo de vida e uso dos recursos naturais de grupos nômades caçador-coletores, além de tribos Tupiguaranis e Aratus, que transitavam frequentemente pelos baixos cursos das bacias hidrográficas. De forma geral, a relação desses grupos com o ambiente de planície era intencionada pela necessidade de obtenção de alimento derivados de frutos do mar (moluscos, peixes, dentre outros), caminhamentos de fácil deslocamento devido ao terreno aplainado, melhor campo de visão para defesa coletiva e locais de fácil acampamento. Dessa forma, subentende-se que a topografia era um atributo chave para as ocupações desse bojo.

Especificamente ao longo das margens do rio Almada, os sítios arqueológicos indicam esse arcabouço de concepções de ocupação mencionado: a textura friável dos solos arenosos favorecia todos os tipos de depósitos de vestígios, onde se destacam nos sítios identificados contínuos amontoados de conchas até sucessivas queimas de material fóssil na estratigrafia arqueológica, consolidando a área como um reduto de uso de recursos naturais por parte das comunidades pré-coloniais. Mesmo não apresentado um uso da terra que caracterizem tais grupos como sedentários, havia uma preferência desses horizontes de ocupações em ambientes com essa paisagem.

Segundo Araújo (2013), possivelmente as zonas de planície funcionavam também como locais de encontro entre as tribos que ocupavam todo o território do Sul da Bahia, sendo comum, por exemplo, a troca de artefatos de caça e alimentos, e intercâmbios de línguas e costumes, já que a Arqueologia da Paisagem remonta a presença desses grupos também em função de simbologias no ambiente. Tais apontamentos são fundamentados no fato de vestígios de diferentes gêneses ocorrerem nos mesmos sítios: como exemplo, nos sítios pré-coloniais ao sul da Lagoa Encantada, foram registradas ocorrências de cerâmica possivelmente de comunidades Aratus adjacentes a lascas de quartzo (rocha) produzidas por grupos caçadores-coletores, bibliograficamente remetidos a cerca de 1000 anos A.P.

Em um dos sítios arqueológicos em área de planície mapeados por Silva (2013), observou-se a ocorrência de material lítico na forma de sílex (Figura 3C), uma rocha que tem sua fonte geológica mais próxima registrada no atual município de Ipiaú, cerca de 100 quilômetros de distância da zona em estudo: o percorrimento ancestral entre os ambientes litorâneos e interioranos nessa região se dava, sobretudo, pelos rios, os quais funcionavam como rotas estabelecidas naturalmente. Essa configuração de conexão hidrográfica permitiu que grupos se deslocassem através do Rio de Contas (com foz a $40 \mathrm{~km}$ a norte da região em estudo) chegado até o litoral, sendo esse o caminho de diversos materiais além do sílex identificados, que foram produtos de escambo na região de Ilhéus.

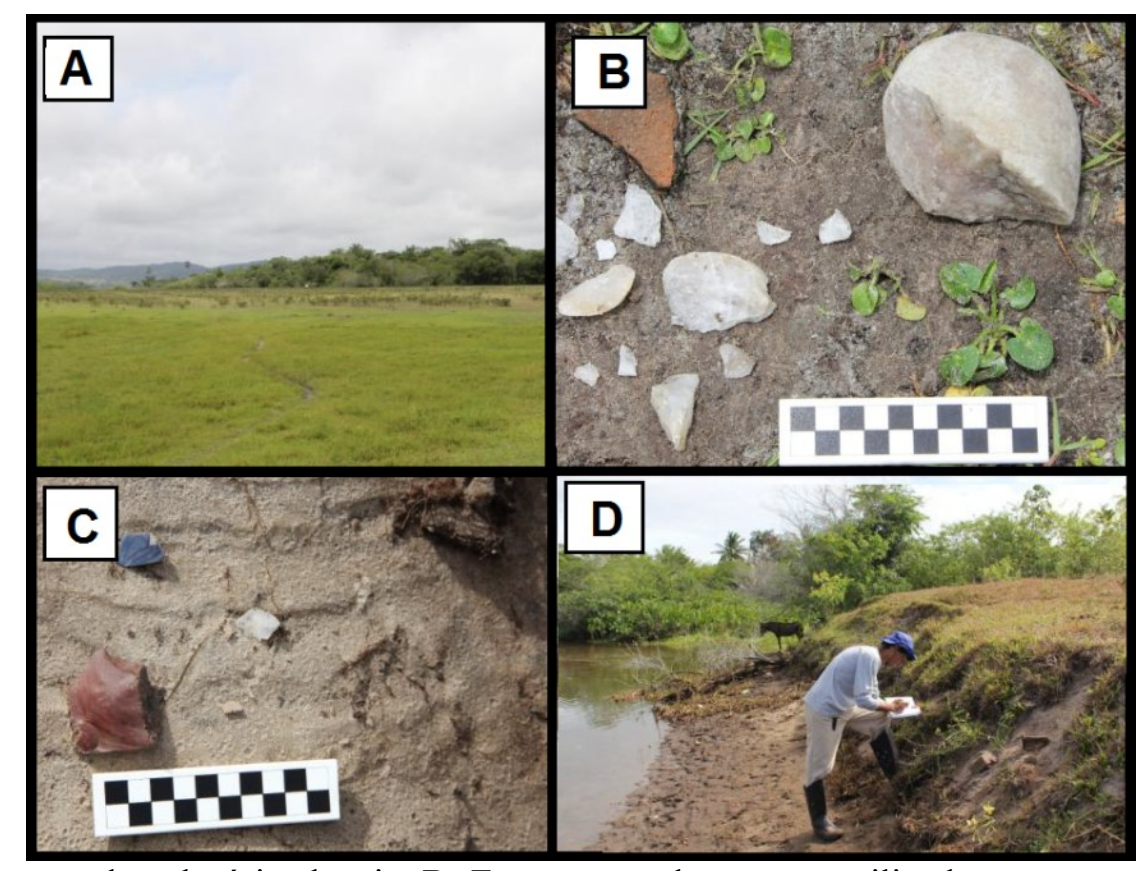

Figura 3: A: Paisagem das planícies locais; B: Fragmentos de quartzo utilizados para corte de caças pelos grupos caçadores coletores; C: Sílex identificado em sítio na margem do rio Almada; D: descrição de sítio em zona estuarina. 


\subsection{Geossistemas de Matrizes Colonais}

As ocupações que remontam as atividades no período colonial do Brasil, que numa linguagem da Ciência Histórica traduz-se como "ocupação histórica", são identificadas na região como atividades de uso da terra que necessitavam fundamentalmente de água. Destaca-se nesse período a predominância de atividades econômicas pautadas na produção de açúcar (para exportação) e farinha (abastecimento interno da colônia). Dessa forma, o padrão de ocorrência desses vestígios é uniforme na paisagem: construções de engenhos e estruturas derivadas nas margens de corpos d'água regionais.

A relação geossistêmica das ocupações desse período com os atributos naturais detinha da seguinte configuração: inicialmente optava-se pelo manejo da terra em áreas de solos mais profundos nas áreas mais interioranas onde há o predomínio de elevações, vales e depressões. Nessas áreas o plantio era processado nos engenhos que necessariamente eram movidos pela força da água, ou seja, tratam-se estruturas presentes nas margens de rios tributários em posições no terreno onde a topografia elevada favorecia quedas d'água pra gerar energia no processamento das rodas de engenho. Os leitos maiores dos rios principais das três bacias hidrográficas, em momentos posteriores a produção e processamento dos insumos, eram utilizados como rotas de escoamento até o Porto de Ilhéus. Assim, a ocorrência dos sítios arqueológicos de matriz histórica não é presente nas zonas de planície.

Segundo Silva (2013), os rios também eram fonte de material de construção para os engenhos e demais construções semiurbanas adjacentes por disponibilizar areia refinada e rochas, que eram untadas como um tipo de cimento formado pela mistura de argilas e conchas. Essa técnica de construção é típica das construções anteriores ao final do Século XIX no Brasil, sobretudo nas áreas litorâneas dos estados da Bahia, Rio de Janeiro e Pernambuco. Esse tipo de técnica, ainda que classificada como rudimentar quando comparada com forma de construir residências e demais estruturas nas vilas coloniais (DIAS e ARAÚJO, 2016), demonstra-se resistente, considerando que atualmente os vestígios dessas construções nas propriedades rurais da região apresentam-se ainda próximos a configuração original (Figura 4B e C).

De forma geral, a água dos rios era represada de forma parcial a ponto de possibilitar um nível de escoamento por gravidade até a roda do engenho. Esses barramentos também eram construídos com matéria prima dos rios. O caminho das águas entre os barramentos e o engenho eram canais de rocha que podem chegar até 50 metros de comprimento, como observado nos sítios arqueológicos próximos ao rio Cachoeira. Favorecida por uma pluviosidade de aproximadamente $2.000 \mathrm{~m}$ anuais e sem estação seca definida, os rios regionais sempre detêm de água superficial ao longo do ano, o que se traduz como mais um dos atributos naturais que favorecem o desenvolvimento econômico regional.

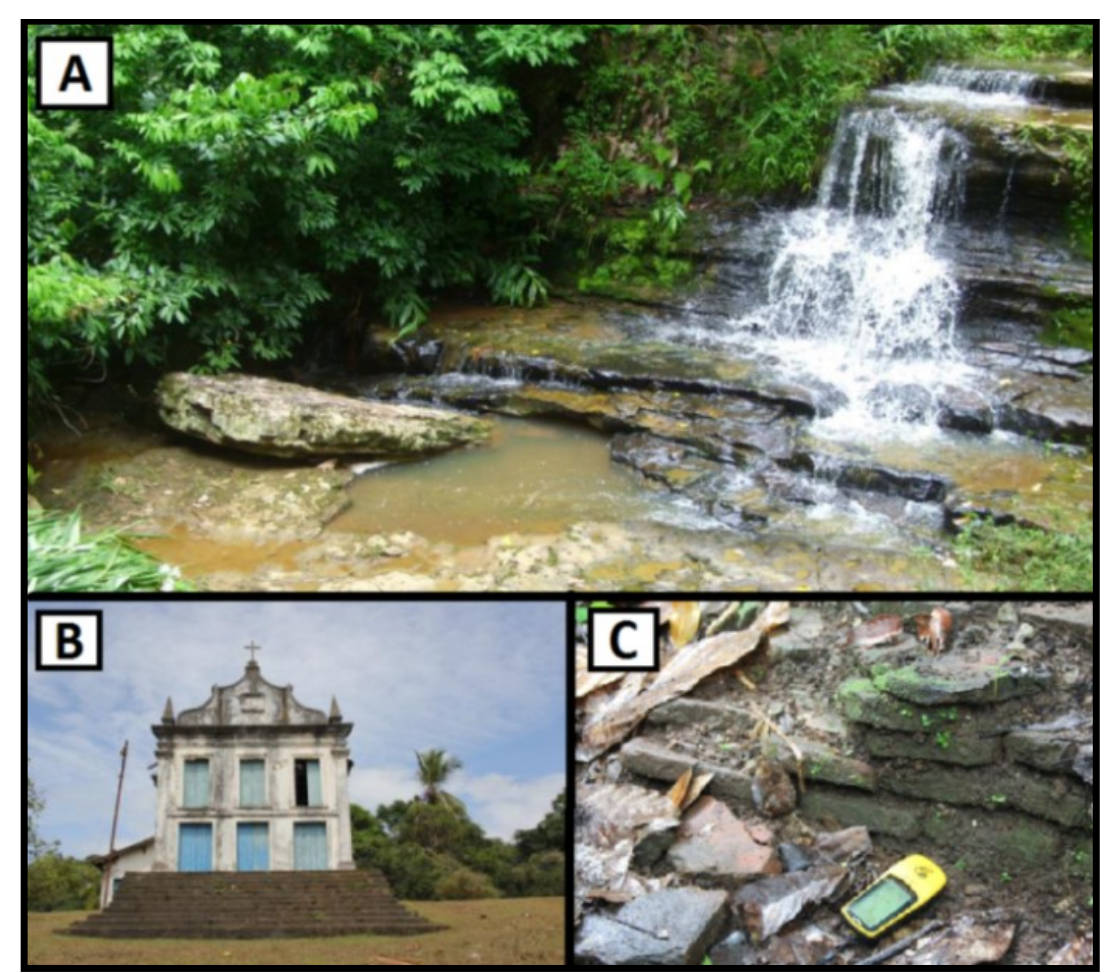

Figura 4: A) Tributário do rio Almada utilizado para represamento de água; B) Templo regional construído no século XVIII; C) Estrutura de pedras de antigo engenho as margens do rio Cachoeira. 
A Lagoa Encantada é um corpo d'água que sempre tem destaque nos mapas regionais devido a sua dimensão de $25 \mathrm{~km}^{2}$ (Figura 5). As ocupações históricas em seu entorno apontam que, em seu setor norte, existiu pelo menos três estruturas de engenho em seu rio formador, processando produções de cana-de açúcar e mandioca cultivados em cerca de 1.1000 hectares no entorno a lagoa. Além de uma simbologia cultural para os aldeões coloniais retratada nos estudos de Araújo (2015) e Silva (2015), a sua imponência também era sinônimo de segurança para a pesca artesanal e escoamento de produção, já que ela se conecta ao sul com o rio Almada. Segundos os autores, mitos e contos são oriundos da época dos engenhos, com destaque para estórias que envolvem a presença de um possível quilombo em suas margens, já que o percorrimento de suas margens em épocas do ano era impossibilitado devido a cheias sazonais.

A possibilidade de pesca e coleta de moluscos nas zonas alagadas ao sul da Lagoa Encantada faz com que esse atributo natural da paisagem local seja reduto de atividades de subsistência desde o tempo pré-colonial, perpassando o período colonial, e observado até os dias de hoje, já que as água da lagoa é doce e sua profundidade média de 12 metros favorece uma abundância de espécies para pesca local.

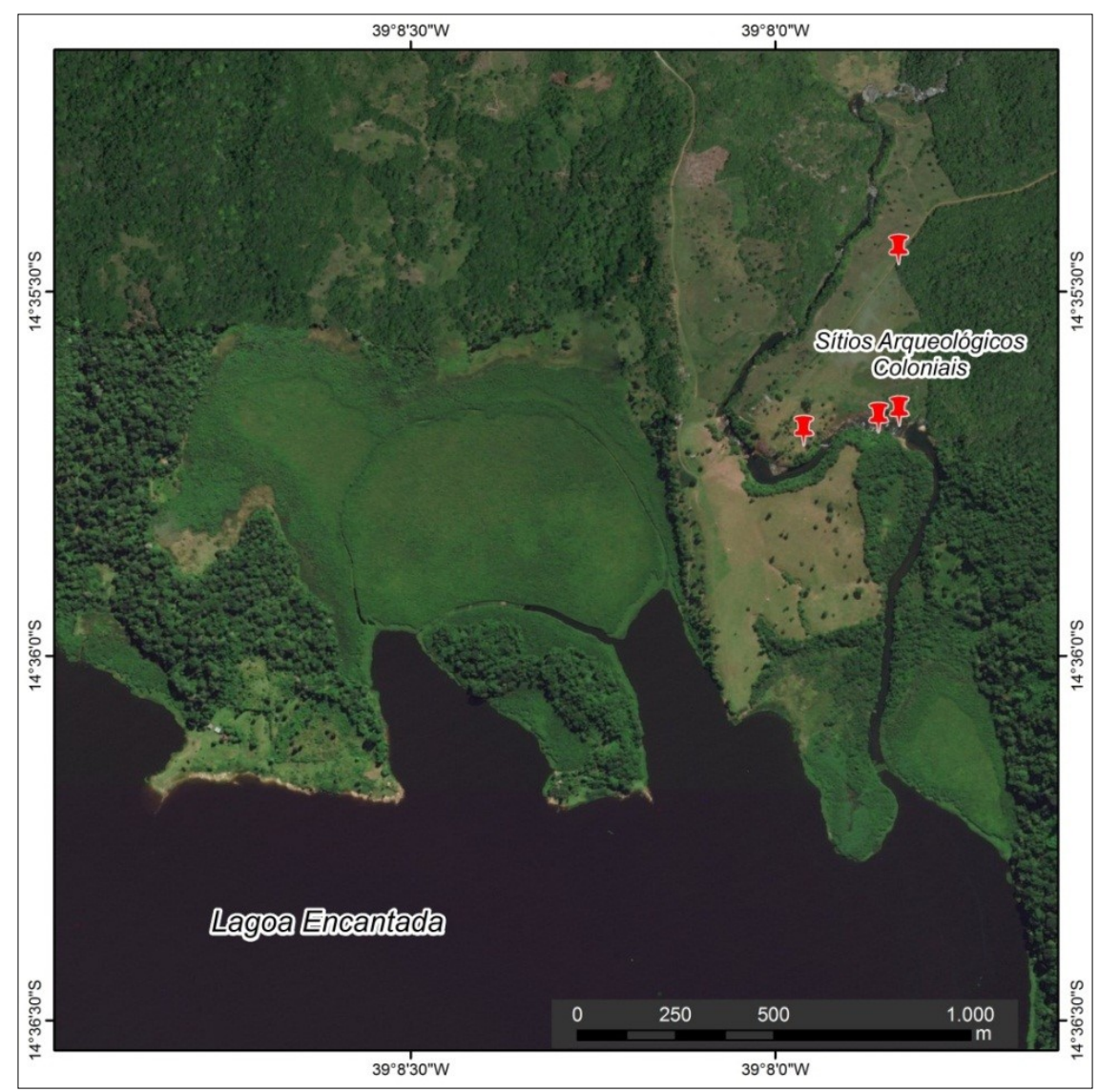

Figura 5: Ocorrências históricas no entorno da Lagoa Encantada

\subsection{Cenários: perspectivas de novas ocorrências}

De forma geral, os 32 pontos de ocorrências arqueológicas que subsidiaram essa pesquisa indicam que há localidades na atual região de Ilhéus cujo devem apresentar informações ainda não mapeadas nos trabalhos desenvolvidos até o momento. O que se resulta da abordagem geossistêmica pode ser entendido como um indicador de cenários ambientais onde novas ocorrências podem surgir e incrementar o arcabouço arqueológico regional. Especificamente, as ocupações pré-coloniais são as que apresentam grandes lacunas para os pesquisadores da área.

De forma análoga, as ocupações ancestrais da região mapeadas até o momento remetem a padrões de ocupação em função de atributos naturais, considerando, sobretudo, a presença de uma hidrografia, pedologia e topografia que favorecem a subsistência humana do ponto de vista ambiental (Quadro 1). A leitura sistêmica desses ambientes visando vestígios, é considerado o principal vetor de novas informações sobra a real simbologia de ocupações ancestrais na região de Ilhéus, seja em contextos socioeconômicos ou estritamente culturais, já que a Arqueologia da Paisagem é utiliza metodologias que se baseiam na percepção (subjetividade) do sujeito no espaço geográfico. 
Quadro 1 - Síntese da relação entre as ocupações ancestrais e os geossistemas locais.

\begin{tabular}{|c|c|c|}
\hline Sistemas Naturais & Características das ocupações pré-coloniais & Características das ocupações coloniais \\
\hline Planícies Argilosas & Caminhamentos, deposição de material cerâmico. & $\begin{array}{c}\text { Acessos as áreas interioranas partindo da } \\
\text { Vila de Ilhéus }\end{array}$ \\
\hline Planícies Arenosas & $\begin{array}{c}\text { Ocorrências de material lítico, deposição de } \\
\text { conchas, estratégias de sobrevivência em } \\
\text { conflitos. }\end{array}$ & $\begin{array}{c}\text { Pecuária de pequena escala (Dias e } \\
\text { Araújo, 2016) }\end{array}$ \\
\hline Elevações Costeiras & $\begin{array}{c}\text { Deposição de material cerâmico, mas com } \\
\text { evidências de locais pontuais. }\end{array}$ & - \\
\hline Depressões e vales & - & $\begin{array}{c}\text { Locais ideais para funcionamento dos } \\
\text { engenhos de cana-de-açúcar e farinha de } \\
\text { mandioca }\end{array}$ \\
\hline Lagoa Encantada & $\begin{array}{c}\text { Deposição de conchas (Sambaqui), pesca e coleta } \\
\text { de moluscos. }\end{array}$ & Escoamento fluvial da produção e pesca. \\
\hline
\end{tabular}

\section{Considerações Finais}

Os geossistemas identificados na região de Ilhéus evidenciam o uso dos recursos naturais de forma categórica nos dois diferentes períodos pretéritos evidenciados pelos vestígios arqueológicos, que demonstra que a concepção de sistemas naturais é construída, ainda que empiricamente, desde momentos anteriores a colonização do território brasileiro. Dessa forma, é possível entender que não somente a água foi força motriz das ocupações no passado, mas diversos outros atributos da paisagem natural desempenharam papel fundamental na disponibilidade de recursos para as atividades de uso da terra e subsistência por parte dos grupos ancestrais e colonos que circulavam pela região. Verifica-se que as atividades de caça, pesca, produção de cana-de-açúcar e mandioca, que em muitas bibliografias são descritas apenas como vocação regional, estão ligadas singularmente a configuração geossistêmica da área.

Considerando que a Arqueologia da Paisagem elenca a paisagem como principal força motriz para o indivíduo construir traços culturais (e eventualmente vestígios materiais), a abordagem geossistêmica corrobora com essa concepção no sentido de que a relação dos atributos naturais é indissociável dos sistemas antrópicos, que vale também em estudos que envolvam ocupações ancestrais. Para a região de Ilhéus, a formatação de eventuais estudos que observem a síntese apresentada nessa pesquisa, podem identificar áreas com potenciais ocorrências arqueológicas, fortalecendo os mecanismos de atuação do IPHAN (Instituto do Patrimônio Histórico e Artístico Nacional) na política de conservação do patrimônio cultual do Brasil.

\section{Agradecimentos}

A infraestrutura do Laboratório de Estudos Climáticos do Instituto de Geociências da Unicamp, tendo como suporte financiamento Fapesp n ${ }^{\circ}$ 18/09401-1.

\section{REFERÊNCIAS}

ALVARES, C. A. STAPE, J.L. SENTELHAS, P.C. Köppen's climate classification map for Brazil. Meteorologische Zeitschrift, v. 22, n. 6, p. 711-728. 2013.

AMORIM, R. R. REIS, C. H. FERREIRA, C. Mapeamento dos geossistemas e dos sistemas antrópicos como subsídio ao estudo de áreas com riscos a inundações no baixo curso da bacia hidrográfica do rio Muriaé (Rio de Janeiro - Brasil). Territorium, nº 24, p. 89-114. 2017

AMORIM, R. R. OLIVEIRA, R. C. Zoneamento ambiental, subsídio ao planejamento no uso e ocupação das terras da costa do descobrimento. Mercator. Fortaleza, v. 12, n. 29, p. 211 - 231, set./dez. 2013.

ARAÚJO, G. S. Mapeamento arqueológico na bacia do rio cachoeira, ilhéus-ba: uso do sig para a identificação e analise de sítios. Anais do XII Congresso de Geografia da Uesc. Ilhéus, Bahia. 10 p. 2011.

ARAÚJO, G. S. Mapeamento Arqueológico no médio curso da Bacia do Rio Cachoeira: um estudo da arqueologia da paisagem, Ilhéus, Bahia. Relatório Final de Pesquisa Científica da Universidade Estadual de Santa Cruz. Financiamento CNPQ. 25 p. 2013

ATTEMA, P. DEHAAS, T.C.A. Villas and farms treads in the Pontine region between 300 BC and 300AD: a landscape archaeological approach. In: Santillo F.B. Klynne, A. (orgs). Roman villas around the Urbs. 
Interaction with lands cape and environment. Proceedings of a conference held at the Swedish Institute in Rome, September, 2004.

BASTIAN, O. GRUNEWALD, K. SYRBE, R. U. Space and time aspects of ecosystem services, using the example of the EU Water Framework Directive. International Journal of Biodiversity Science, Ecosystem Services \& Management, v. 8, n. 1-2, p. 5-16, 2012.

BASTIAN, O. GRUNEWALD, K. KHOROSHEV, A. V. The significance of geosystem and landscape concepts for the assessment of ecosystem services: exemplified in a case study in Russia. Landscape Ecology, v. 30, n. 7, p. 1145-1164, 2015.

BEVAN, A. The rural landscape of Neopalatial Kythera: A GIS perspective. Journal of Mediterranean Archaeology, vol. 15, p. 217-256, 2002.

BEVAN, A. CONOLLY, J. GIS, archaeological survey, and landscape archaeology on the island of Kythera, Greece. Journal of Field Archaeology, v. 29, n. 1-2, p. 123-138, 2004.

BRADLEY, R. An Archaeology of Natural Places. Routledge, London. 2000.

BROWN, A. G. BAILEY, G. PASSMORE, D. Environments and landscape change. In: FOWLER, C. HARDING, J. HOFMANN, D (Eds.). The Oxford Handbook of Neolithic Europe. Oxford University Press, Oxford. 2015.

BURKHARD, B. DE GROOT, R. COSTANZA, R. Solutions for sustaining natural capital and ecosystem services. Ecological Indicators, $n^{\circ}$ 21, p. 1-6. 2012.

BURKHARD, B. KANDZIORA, M. HOU, Y. Ecosystem Service Potentials, Flows and Demands-Concepts for Spatial Localization, Indication and Quantification. Landscape, vol. 34, p. 2-12. 2014.

BUTZER, K. W. Archaeology as human ecology: method and theory for a contextual approach. Cambridge University Press, 1982.

CASPARIA, G. PLETSC, G. BALZD, T. FUF, B. Landscape archaeology in the Chinese Altai Mountains Survey of the Heiliutan Basin. Archaeological Research in Asia, no 10, p. 48-53. 2017.

CAVALCANTI, I. F. Tempo e clima no Brasil. Oficina de textos, São Paulo. 2016.

CHLACHULA, J. Pleistocene climate change, natural environments and palaeolithic occupation of the Altai area, west-central Siberia. Quaternary International, vol. 81, p.131-167, 2001. https://doi.org/10.1016/S1040-6182(01)00023-4.

CLENDENON, C. Karst hydrology in ancient myths from Arcadia and Argolis, Greece. Acta Carsologica, vol. 38, p. 145-154. 2009.

CORTELETTI, R. R. DICKAU, P. DEBLASIS. IRIARTE, J. S. Revisiting the economy and mobility of southern proto-Jê (Taquara-Itararé) groups in the southern Brazilian highlands: starch grain and phytholiths analyses from the Bonin site, Urubici, Brazil. Journal of Archaeological Sciences 58: 46-61.2015.

DEBLASIS, P. FISH, P. GASPAR, M. FISH, S. Some References for the Discussion of Complexity Among the Sambaqui Moundbuilders from the Southern Shores of Brazil. Revista de Arqueologia Americana. México, D.F. 15, p. 75-106, 1998.

DIAS, M. H. ARAÚJO, G. S. Ocupação territorial em uma fronteira indígena do sul da Bahia: Una e Olivença em meados do século XIX. Territórios e Fronteiras, v. 9, p. 215-235, 2016.

DIAS, M. H. MORALES, W. F. GOMES, R. L. História, Arqueologia e Georreferenciamento na percepção da ocupação territorial da vila de Ilhéus (Bahia, Brasil): período pré-colonial ao século XVII. In: Documentos de Trabajo do XIV Congreso Internacional de Historia Agraria. Congreso Internacional de la Seha, Badajós, 2013.

DOYLE, J. GARRISON, T. HOUSTON, S. Watchful realms: integrating GIS analysis and political history in teh southern Maya low-lands. Antiquity, vol. 86, p. 792-807. 2011.

ENGLAND, A. EASTWOOD, W.J. ROBERTS, C.N.TURNER, R.HALDON, J.F. Historical landscape change in Cappadocia (centralTurkey): a palaeoecological investigation of annually laminated sediments from Nar lake. The Holocene, vol. 18, p.1229-1245. 2008.

FIONA, W. A view from the forest floor: the impact of logging on indigenous peoples. Brazil. Botanical Journal of the Linne an Society, vol. 122, p. 75-82. 1996. 
FRANCO, G. B. MARQUES, E. A. G. GOMES, R. L. CHAGAS, C. S. SOUZA, C. M. P. BETIM, L. S. Fragilidade ambiental da bacia hidrográfica do rio Almada - Bahia. Revista de Geografia (Recife), v. 28, n. 2, p. 187-205, 2011.

GAGARINOVA, O. V. KOVALCHUK, O. A. Assessment of anthropogenic impacts on landscape hydrological complexes. Geographical and Natural Resources, n.31, pp. 291-295, 2010

GASPAR, M. DEBLASIS, P. FISH, S. FISH, P. Sambaqui (Shell Mound) Societies of Coastal Brazil. In: SILVERMAN, H. ISBELL, W. (eds). Handbook of South American Archaeology. New York: Springer, 2008, p. 319-338.

GHEYLE, W. High lands and Steppes: An Analysis of the Changing Archaeological Landscape of the Altay Mountains From the Neolithic to the Ethnographic Period. PhDdiss. University of Ghent. 2009.

IRIARTE, J. S. MOEHLECKE, C. FRADLEY, M. GILLAM C. J. Sacred landscapes of the southern Brazilian highlands: understanding southern proto-Jê mound and enclosure complexes. Journal of Anthropological Archaeology, 32: 74-96. 2013.

JAICHAND, V. SAMPAIO, A. A. "Dam and Be Damned: The Adverse Impacts of Belo Monte on Indigenous Peoples in Brazil." Human Rights Quarterly, vol. 35 no. 2, 2013, pp. 408-447. Project MUSE.

KANTNER, J. The archaeology of regions: From discrete analytical toolkit to ubiquitous spatial perspective. Journal of Archaeological Research, vol. 16, p. 37-81, 2008.

KARKANAS, P. PAVLOPOULOS,K. KOULI, K. NTINOU,M. TSARTSIDOU,G. FACORELLIS,Y. TSOUROU,T. Paleo environment sands it formation processes at the Neolithic lake side settlement of Dispilio, Kastoria, northern Greece. Geoarchaeology, vol. 26, p. 83-117. 2011.

OLIVEIRA, M. D. B. G. KLOKLER, D. BIANCHINI, G. F. Strategic archaeology: holistic approaches to the construction of ancient mounds. Boletim do Museu Paraense Emílio Goeldi, vol. 8, p. 517-533. 2013.

PEDREIRA, A. J. WAELE, B. Contemporaneous evolution of the Palaeoproterozoic- Mesoproterozoic sedimentary basins of the São Francisco-Congo Craton. Geological Society Special Publications, n. 294, p. 33-48. 2008

PEREIRA, L. S. PEREIRA, I.S. Geodiversity of Parahyba in the colonial period. Mercator, vol. 16, p.160$169,2017$.

RISSETO, H. R. What can GIS and 3D mean for landscape archaeology? Journal of Archaeological Science, vol. 84, p. 10-21. 2017. doi:10.1016/j.jas.2017.05.005

RISSETTO, H. R. LANDAU, K. Movement as a means of social (re) production: using GIS to measure social integration across urban landscapes. Journal of Archaeological Science, vol. 41, p. 365-375. 2014.

RIVERA, M. ROTHHAMMER, F. Relaciones interetnicas entre pueblos de la floresta tropical y areas desertticas del norte de Chile, ca. 5000 A.C.: la tradicion chinchorro. Revista do CEPA, Santa Cruz do Sul, 17, 20, p. 437-456, 1990.

ROOSEVELT, A. HOUSLEY, R. IMAZIO-SILVEIRA, M. MARANCA, S JOHNSON, R. Eighth Millennium Pottery from a Prehistoric Shell Midden in the Brazilian Amazon. Science, Vol. 254, p. 16211624, 1991.

SAKAI, K. Archaeological investigations in São Paulo, Brazil. Anthropological papers of the Anthropological Society of Tokyo, v. 87, p. 25-52, 1979.

SANJUÁN, L. G. Introducción al reconocimiento y análisis arqueológico del territorio: Leonardo García Sanjuán; prólogo de Francisco Burillo Mozota. Ariel, 2005.

SOCHAVA, V. B. Geography and Ecology. Soviet Geography, v.12, n.:5, p. 277-293, 1971.

SEI. Superintendência de Estudos Econômicos e Sociais da Bahia. Mapas digitalizados do Estado da Bahia: base de dados. Salvador: SEI. (CD-ROM). 2004

SILVA, K. B. Mapeamento Arqueológico das Bacias dos rios Cachoeira e Almada: Um estudo de Arqueologia Regional da Universidade Estadual de Santa Cruz, Ilhéus - Bahia. Relatório final de Pesquisa Científica da Universidade Estadual de Santa Cruz. Financiamento FAPESB nº 1928/2011. 17 p. 2012.

SILVA, K. B. Mapeamento arqueológico no médio e baixo curso da bacia do rio Almada: um estudo da Arqueologia da paisagem em Ilhéus, Bahia. Relatório final de pesquisa científica da Universidade Estadual de Santa Cruz. Financiamento FAPESB n 1305/2012. 23 p. 2013. 
SILVA, K. B. GOMES, R. L. REGO, N. A. C. Social and Environmental Hydrographics Implications of the land use in the Plain And Coastal Boards Between Ilhéus and Olivença - Bahia. Journal of Hyperspectral Remote Sensing, v. 5, p. 013-026, 2015.

SCHWERIN, J. RISSETTO, H. R. REMONDINO, F. AGUGIARO, G. GIRARDI, G. The Maya Arch 3D project: A 3D WebGIS for analyzing ancient architecture and landscapes, Literary and Linguistic Computing, Vol. 28, p. 736-753. 2013.

WAGNER, G. P. The Origins of the Brazilian Sambaquis (Shell-Mounds): From a Historical Perspective. Cadernos do LEPAARQ, vol. 11, p. 45-66, 2014.

WALSHA, K. BROWNB, A. G. GOURLEYA, B. SCAIFEB, R. Archaeology, hydrogeology and geomythology in the Stymphalos valley. Journal of Archaeological Science: Reports, vol. 1, p. 1- 9. 2017. 